\title{
Capitalismo sob a hegemonia financeira e o poder no Brasil
}

Le capitalisme sous l'hégémonie financière et le pouvoir au Brésil

Capitalismo bajo hegemonía financiera y el poder en Brasil

Call for debate on financial hegemony and power in Brazil

\section{Roberto Moraes Pessanha}

\section{Q OpenEdition}

Journals

\section{Edição electrónica}

URL: https://journals.openedition.org/espacoeconomia/19705

DOI: 10.4000/espacoeconomia.19705

ISSN: 2317-7837

\section{Editora}

Núcleo de Pesquisa Espaço \& Economia

\section{Refêrencia eletrónica}

Roberto Moraes Pessanha, «Capitalismo sob a hegemonia financeira e o poder no Brasil», Espaço e Economia [Online], 21 | 2021, posto online no dia 13 julho 2021, consultado o 17 julho 2021. URL: http://journals.openedition.org/espacoeconomia/19705 ; DOl: https://doi.org/10.4000/ espacoeconomia.19705

Este documento foi criado de forma automática no dia 17 julho 2021.

\section{cc) (1) (ㅇ)}

Espaço e Economia - Revista brasileira de geografia econômica est mise à disposition selon les termes de la licence Creative Commons Attribution - Pas d'Utilisation Commerciale - Partage dans les Mêmes Conditions 4.0 International. 


\title{
Capitalismo sob a hegemonia financeira e o poder no Brasil
}

\author{
Le capitalisme sous l'hégémonie financière et le pouvoir au Brésil \\ Capitalismo bajo hegemonía financiera y el poder en Brasil \\ Call for debate on financial hegemony and power in Brazil
}

Roberto Moraes Pessanha

\section{NOTA DO EDITOR}

O artigo em tela derivou do debate ao lado de Ladislaw Dowbor promovido pelo Instituto Amsur e intitulado Capital financeiro: hegemonia e poder no Brasil em $4 \mathrm{de}$ julho de 2021. Disponível em: https://youtu.be/TC5ghTh1VC8

1 As finanças alcançaram a condição de centro dinâmico da economia e assim promovem uma enorme extração de valor da economia real. Vive-se sob a espécie de um parasitismo que se alimenta de altíssimos rendimentos, numa lógica de risco-retorno de curto prazo, capturados da economia real. Tudo se transforma em ativos em meio a colossais inovações financeiras que se ampliam com o potencial da tecnologia e das plataformas digitais. Empresas de vários portes em diferentes setores econômicos e concessões de serviços públicos são cada vez mais controlados por agentes e gestoras dos fundos financeiros que assim redefinem o modus operandi do setor produtivo e da sociedade. Tem-se aí um quadro bem distinto do que havia há duas décadas, quando a intermediação financeira era feita basicamente pelos bancos tradicionais. $O$ mercado aumentou seu protagonismo e paulatinamente passa a controlar a economia, a política e a dirigir políticas econômicas setoriais e territoriais no lugar do Estado, mais fragilizado em sua capacidade regulatória, menor autonomia e soberania nacional. é preciso melhor compreender este quadro dentro do esforço político para se retomar o projeto de desenvolvimento nacional com inclusão social e redução das desigualdades. 
Para facilitar a leitura e o debate do tema irei dividir a apresentação do tema por pontos:

2 1. A conversa aqui proposta é relativamente simples. Comentar sobre como a hegemonia financeira foi se constituindo, em especial depois de 2008/2009; como o rentismo foi se entranhando na economia real, de onde recolhe excedentes cada vez mais expressivos, que agora aparecem sob a forma de capitalização nos saldos dos patrimônios dos fundos financeiros e no aumento do $\mathrm{n}^{\circ}$ de investidores no mercado de capitais e na B3.

3 2. Um processo de ampliação da dominação financeira com estratégias em que os donos dinheiros andar de cima - passaram a definir e a controlar a atuação da produção - na economia real - em diferentes setores no território.

4 3. E no campo da Economia Política - que penso mais interessa a essa conversa -, analisar como esses processos se articulam com as relações de poder e com a busca de maior controle sobre o Estado no Brasil atual, de uma forma bem distinta daquela que existia no país há duas décadas. As relações Estado-Mercado-Sociedade estão rapidamente se alterando com o Estado sendo deslocado e perdendo o protagonismo para o Mercado.

5 4. Provavelmente, nós estamos diante de transformações importantes nesta fase de deslocamento do capitalismo, o que aumenta as dificuldades de observar o fenômeno.

6 5. Assim, talvez seja oportuno lembrar Braudel (e seus ciclos históricos). Nos últimos 200 anos, em termos de sistema, saímos de uma fase hegemonicamente comercial, para o capitalismo industrial e agora, estamos sob a hegemonia e o protagonismo das finanças e da dominação tecnológica e digital. Entramos num novo padrão mais radical de acumulação. Padrão de acumulação em que os lucros são obtidos mais pelos canais financeiros do que por meio das atividades comercial e produtiva. Há uma extração de valor nas entranhas da economia capitalista.

7 6. Um padrão de acumulação e de capitalização, onde quase tudo (quase todos os negócios) se tornam ativos. $\mathrm{E}$, como ativos, os negócios - mesmo muito diferentes passam a ser melhor comparados pelos investidores (pelos donos dos dinheiros), para assim, melhor definir onde e em quê investir seus dinheiros. A lógica do andar superior das finanças e da pirâmide do capital (Arrighi, 1997). [1] [2] 


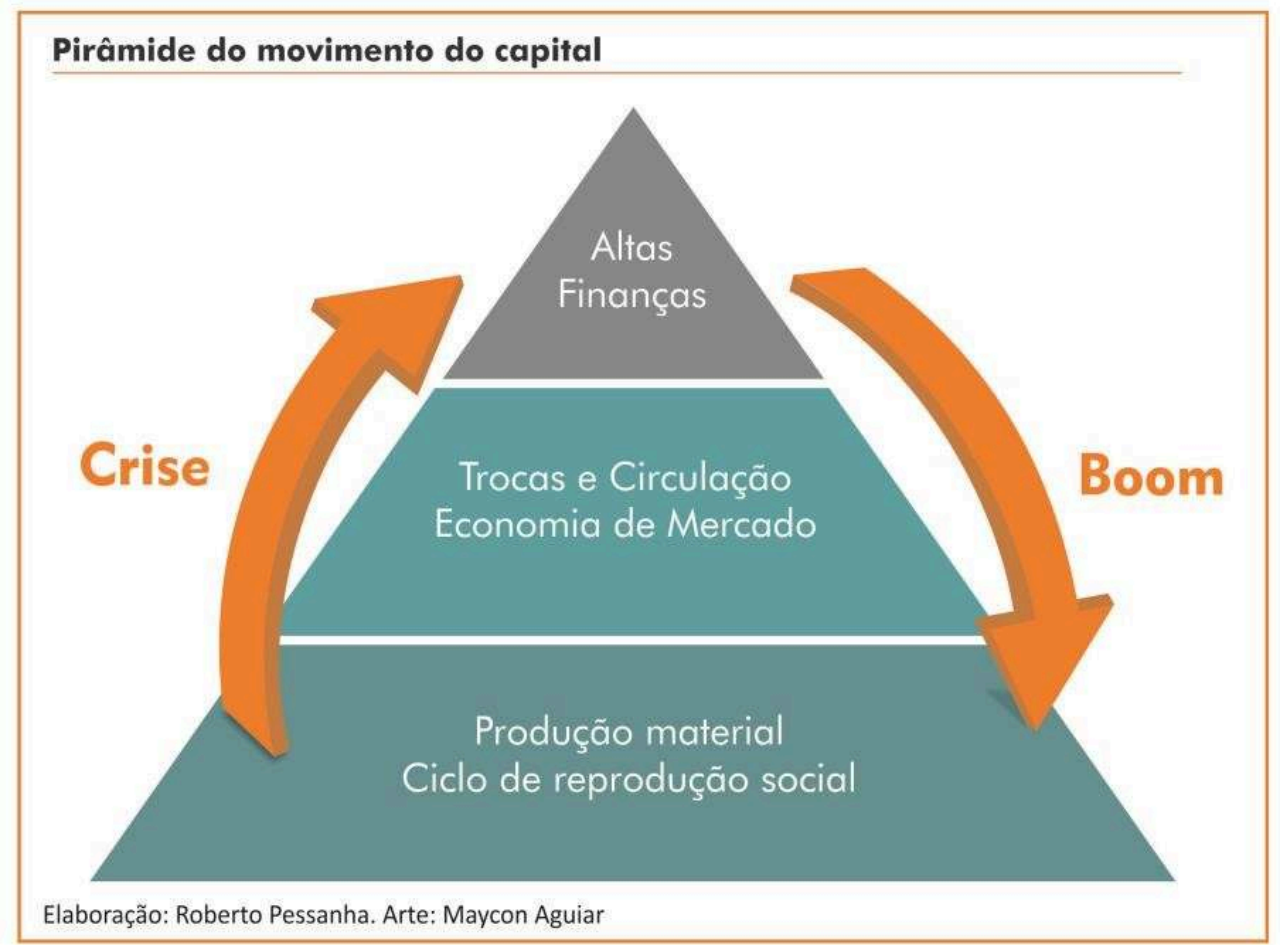

7. Saímos de um capitalismo da fase hegemônica industrial, de um circuito financeiro bancário que fazia a intermediação entre a produção e o consumo, dentro da tríade marxiana: "produção - circulação - consumo" e constituía o Modo do Produção Capitalista (MPC), para paulatinamente, entrar num circuito financeiro para um circuito financeiro dos fundos e do mercado de capitais, onde o esquema tradicional ainda convive com estas várias e novas formas de inovação financeira. [2] [3]

8. Os excedentes da poupança das famílias e das empresas não são mais majoritariamente colocados nos bancos tradicionais, para fazer a intermediação de capital até os captadores que buscam recursos (créditos) para empreender. Neste caso torna-se paradigmático, observar o movimento dos excedentes das famílias ricas, que usam o "family-office" para investimentos em diferentes fundos financeiros e outros papeis do mercado de capitais. Ainda mais simbólico, é o movimento da família Abílio Diniz, oriunda do comércio de atacados, passa dono de rede de supermercados, acionista de rede francesa e hoje se tornou gestor de ativos de fundo financeiro. [4] [5]

9. Há mudanças na forma de intermediação do circuito financeiro com os fundos e com o mercado de capitais. Na verdade, esse processo vai deixando de ser intermediação e passa, paulatinamente, a se constituir num circuito de capitalização, aquisições, incorporações e fusões com controle da produção, já considerada como um ativo. 


\section{Circuito Financeiro dos Fundos}

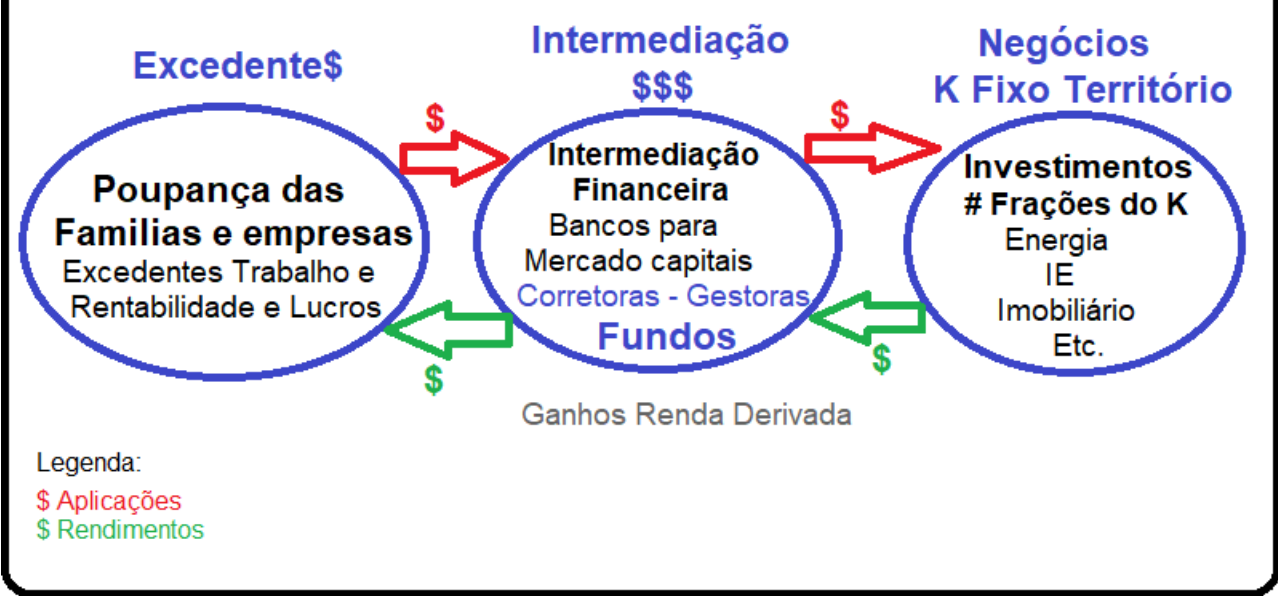

PS.: Leitura e interpretação inspirada em SANFELICI, Daniel. 2019. [6]

11 10. A partir da leitura deste processo se percebe como as finanças foram ganhando um papel central. As finanças, de forma paulatina, mas crescente, estão se tornando o "centro dinâmico da economia", característico dessa fase do "capitalismo hegemonicamente financeiro".

12 11. Não se pode falar das finanças intermediando a "criação de valor", como costumam defender os economistas neoclássicos. Não se trata disso e sim de uma lógica que é, fundamentalmente, de extração de valor. Uma espécie de parasitismo junto à economia real. Assim, não cabe mais falar de intermediação financeira bancária e sim, uma lógica de "riscos - retorno - em curto prazos" e com altíssima rentabilidade dos ativos controlados pelos donos dos dinheiros, os rentistas.

13 12. Se trata de uma nova forma de repartição da riqueza produzida pelo trabalho Uma etapa ainda mais radical do regime de acumulação e de extração de valor. Um "capitalismo de cassino" na leitura do Minsky (década de 90), ou "capitalismo da gestão de ativos", na leitura mais recente da Mariana Mazzucato. [7] Talvez, possa ser falado em "rodadas de neoliberalismo", como costuma se referir o professor Carlos Brandão.

13. Os movimentos que os donos dos ativos fazem é de opção entre os setores e frações do capital. Eles querem saber quais são aqueles que negócios que oferecem maiores rendimentos, menores riscos e em prazos mais curtos.

15 14. Assim, caberia as perguntas: como esse processo e esses movimentos estão se desenrolando? Quais a estratégias e processos estão em curso? Como a hegemonia financeira foi se tornando cada vez mais potente e parasitária da economia real da qual depende e se deriva?

16 15. Aparentemente, há aí um movimento dialético de aproximação e distanciamento entre as finanças e a economia real. Aproximação quando os donos do andar de cima das finanças em se enraízam ao território para aporte em capital fixo na base da pirâmide do capital. Distanciamento quando o capital se realiza e retorna ampliado ao andar superior dos donos dos dinheiros. 
17 16. Observa-se o número colossal de "inovações financeiras" ampliadas pelo potencial da tecnologia e das plataformas digitais. Assim, o mercado de capitais nacional enlaçado aos fundos globais vai se tornando instrumentos de vampirização da renda e da riqueza da economia real.

18 17. É preciso pois, identificar quais são os instrumentos e estratégias que estão sendo utilizados. Alguns estudos mais recentes têm oferecido pistas importantes, sobre esse processo que possui dinâmicas similares e distintas, no centro e na periferia do capitalismo. Assim, é preciso observar esses movimentos do capital aqui no Brasil, no sul global.

19 18. As empresas e parte de setores econômicos cada vez mais são controladas pelos agentes, fundos financeiros e por suas gestoras. Os fundos nomeiam os CEOs destas empresas, com mandatos e metas, assim como os jogadores de futebol. Os CEOs e gerentes passam a ter carreira solo, um portfólio de atuação. Esses dirigentes dos donos dos dinheiros costumam ter como prática a busca de resultados de curto prazo, com cortes de custos e pessoal. Promovem a tal reengenharia, falam em stakeholders, sustentabilidade e agora usam o acrônimo ESG, quase como um mantra. A luta desenfreada e cruel deles tende a ser sempre aquela que busca por resultados, encima especialmente, da redução de custos e com enormes pressões, para obtenção de maior rentabilidade e taxas de lucros sobre o trabalho.

19. Nesse processo torna-se evidente, a "prevalência de uma lógica acionária" que traz embutida estas novas formas de "governança empresarial".

21 20. Os fundos financeiros e as empresas controladas por elas planejam e querem taxas de lucros maiores, o que acaba exigindo condições de trabalho mais precarizadas. Isso explica o mantra das "reformas neoliberais": trabalhista e previdenciária, em especial.

22 21.Essa lógica acionária dos fundos também traz repercussões no campo federativo e das relações de poder, levando governadores e prefeitos a buscarem projetos, capitais de investidores destes fundos, no esforço de busca de ações que gerem emprego e renda.

23 22. Essa lógica que fez crescer, arranjos institucionais (entre agentes de investidores, empresas e governos), que aparecem nos planos de "desenvolvimento regional/local com geração de renda" e projetos que passei a chamar de "projetos-prateleiras".

24 23. As gestoras de fundos financeiros optam por alguns setores econômicos, mas hoje já estão presentes em todos os setores da economia como mostro no meu livro sobre os fundos. Com investimentos desde a infraestrutura (IE), setor imobiliário (FII, FIP), petróleo e infraestrutura. Vide caso das vendas das malhas de gasodutos da Petrobras 9,5 mil km e controle acionário de outras subsidiárias. [8].

25 24. Além disso, é importante observar como as gestoras dos fundos financeiros vão transformando quase tudo em ativos e assim avançam para controles de setores do comércio, o varejo incluindo o comércio de hortifrútis e até de controle da concessão de cemitérios. [9]

25. Porém, hoje no Brasil, em boa parte estão atrás das oportunidades ligadas às concessões (eletricidade, água e esgoto, rodovias, limpeza urbana, transporte urbano, portos e aeroportos...). Vide caso da Cedae, Eletrobras (em curso) e outros. [10] 

base de infraestrutura já instalada; têm garantia de financiamento governamental barato; não têm necessidade de licenciamento ambiental e o melhor, são setores (água/ esgoto, lixo, eletricidade, transporte público, etc.), que possuem fluxos de capital imediato pela prestação do serviço já em curso.

27. Repito, essa opção dos investidores se dá porque se trata de setores de baixo risco e que possuem fluxos permanentes de capital. Os tais "marcos legais" que garantem duas questões mais importantes para os investidores: flexibilidade que significa poder entrar e sair do negócio e/ou setor. Garantia de altas tarifas que traga ótima e crescente remuneração aos investidores.

28. Assim, os fundos financeiros passaram a ser instrumentos indispensáveis para essa nova lógica, porque oferecem a hipermobilidade do capital (entre as frações e os espaços) - movimento horizontal - ou no circuito do valor (Arrighi, 1997) desde a base da pirâmide social, onde está alocado o capital fixo no território, ao andar superior das altas finanças - movimento vertical. [1] [2]

29. Abaixo dois quadros mostram a evolução do patrimônio dos fundos financeiros no Brasil nos últimos quatorze anos. Um primeiro são valores reais e absolutos, sem correção e o segundo quadro com valores atualizados pelo IGP. Os dados foram extraídos do site do Anbima. [11]

Quadro 1: Evolução do patrimônio total dos fundos financeiros no Brasil (2008-2021 até junho), em valores absolutos em R\$ trilhão

\begin{tabular}{|l|l|l|l|l|l|l|l|l|l|l|l|l|l|}
\hline \multicolumn{10}{|c|}{ Evolução do patrimônio líquido dos fundos financeiros no Brasil (2008-2021*) } \\
Valores reais e absolutos (constantes) em R\$ trilhão \\
\hline $\mathbf{2 0 0 8}$ & $\mathbf{2 0 0 9}$ & $\mathbf{2 0 1 0}$ & $\mathbf{2 0 1 1}$ & $\mathbf{2 0 1 2}$ & $\mathbf{2 0 1 3}$ & $\mathbf{2 0 1 4}$ & $\mathbf{2 0 1 5}$ & $\mathbf{2 0 1 6}$ & $\mathbf{2 0 1 7}$ & $\mathbf{2 0 1 8}$ & $\mathbf{2 0 1 9}$ & $\mathbf{2 0 2 0}$ & $\begin{array}{l}\mathbf{2 0 2 1 *} \\
\text { Até junho }\end{array}$ \\
\hline $\mathbf{1 , 1 2 6}$ & 1,403 & 1,671 & 1,942 & 2,272 & 2,471 & 2,693 & 2,997 & 3,497 & 4,152 & 4,640 & 5,470 & 6,064 & $\mathbf{6 , 5 8 5}$ \\
\hline
\end{tabular}

Quadro 2: Evolução do patrimônio total dos fundos financeiros no Brasil (2008-2021 até junho), em valores atualizados pelo índice IGP-DI em R\$ trilhão

\begin{tabular}{|c|c|c|c|c|c|c|c|c|c|c|c|c|c|}
\hline \multicolumn{14}{|c|}{$\begin{array}{l}\text { Evolução do patrimônio líquido dos fundos financeiros no Brasil (2008-2021*) } \\
\text { Valores atualizados pelo IGP-DI até abril } 2021 \text { em R\$̣ trilhão }\end{array}$} \\
\hline 2008 & 2009 & 2010 & 2011 & 2012 & 2013 & 2014 & 2015 & 2016 & 2017 & 2018 & 2019 & 2020 & $\begin{array}{l}\text { 2021* } \\
\text { Até junho }\end{array}$ \\
\hline 2,830 & 3,590 & 3,860 & 4,249 & 4,635 & 4,778 & 5,002 & 5,032 & 5,449 & 6,554 & 6,758 & 7,561 & 6,754 & 6,585 \\
\hline \multicolumn{11}{|c|}{ Elaboração do autor: PESSANHA, 2021. Fonte: Anbim } & & & \\
\hline
\end{tabular}

31 30. Em valores absolutos e sem correções, os fundos financeiros no Brasil, segundo

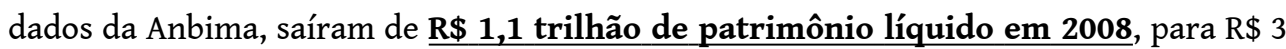
trilhões em 2015 e $\mathbf{R} \mathbf{\$}$ 6,585 trilhões ao final $1^{\circ}$ semestre de 2021. É um crescimento espantoso na forma de reunir excedentes presentes na sociedade. Nesse ritmo, em 2019, pelos valores hoje corrigidos pela inflação, esse volume ultrapassou o PIB do Brasil e tende a voltar a ultrapassar em valores absolutos até 2023. Embora, deva se dizer que se trata de uma comparação impertinente, pois o PIB é referente à economia real medido anualmente e o patrimônio dos fundos se referem aos valores de mercado de seus ativos, portanto, se referem a valor fictício. 
32 31. Nesta análise vale citar um destes tipos de fundo financeiro: o Imobiliário (FFI), muito em voga e na moda atualmente. Em 2009, eram 2 mil investidores em FII no Brasil. Em agosto de 2020, os FII já tinham ultrapassado a 1 milhão de investidores (quotistas) e o Valor Invest, previu em janeiro deste ano, que os FII passarão de 2 milhões de investidores até o final de 2021 . Sendo $74 \%$ de investidores como pessoas físicas (CPFs). [12]

32. Outro exemplo, vinculado a esse movimento de nova forma de recolhimento de excedentes e dinâmica da capitalização no Brasil é o número de investidores na Bolsa de Valores, a B3. Em abril de 2019 tinha chegado a 1 milhão. Em março de 2020, estava em 2 milhões; e em março de 2021 chegou a 3,561 investidores na B3, por $\underline{\mathrm{CPF}}$, com um saldo de quase $1 / 2$ trilhão (R\$ 482 bilhões), enquanto a poupança tem $\mathrm{R} \$ 1$ trilhão. [13]

33. Segundo a Anbima, o Brasil tem um mercado de capitais dos mais sofisticados entre as economias capitalistas do mundo. É o $13^{\circ}$ maior mercado de capitais; o $\underline{\text { 3o maior }}$ mercado de derivativos e a $11^{\mathrm{a}}$ maior indústria de fundos do mundo.

Figura 3: Evolução do número de investidores em Fundos Imobiliários (FII) no Brasil

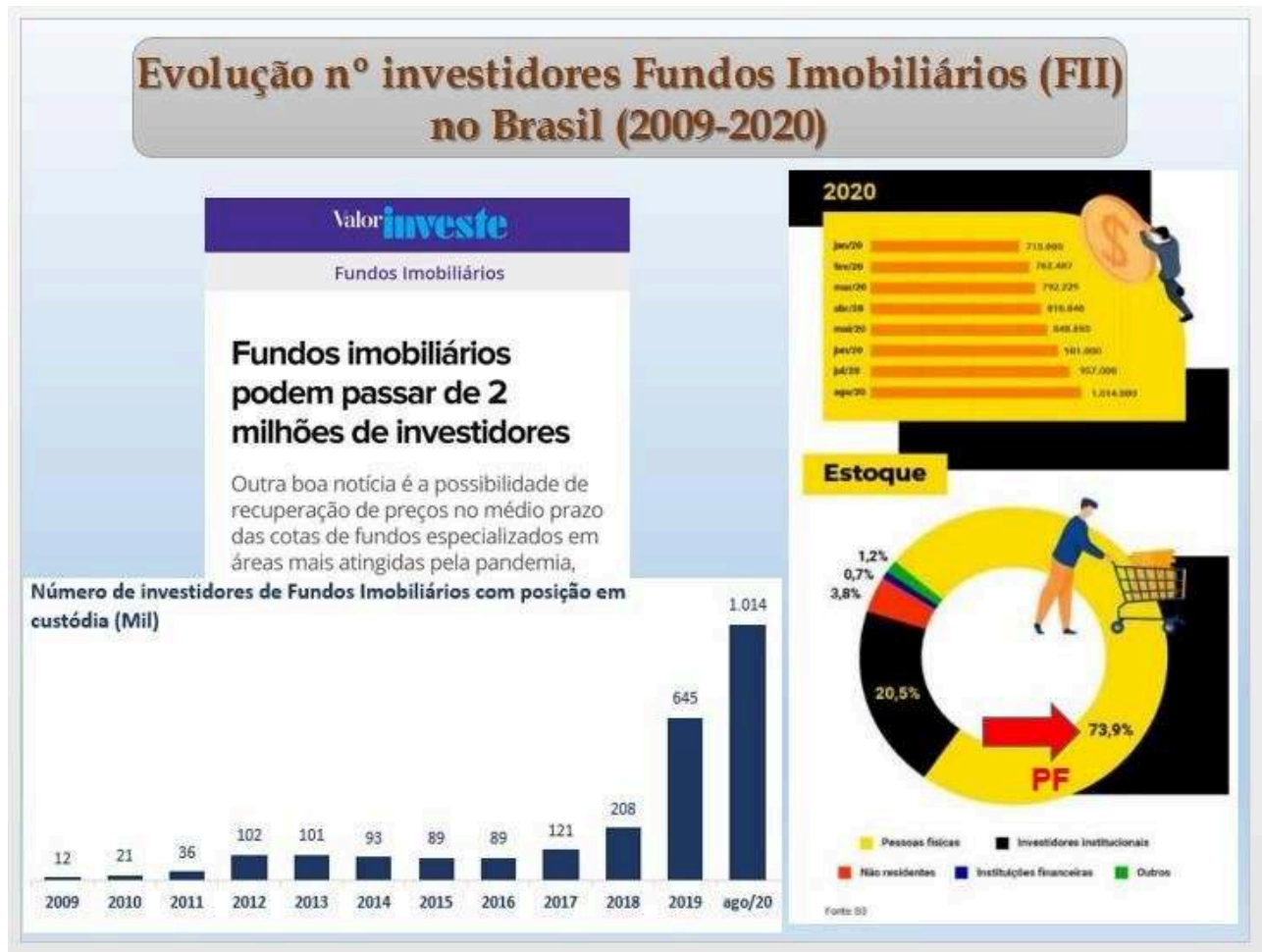




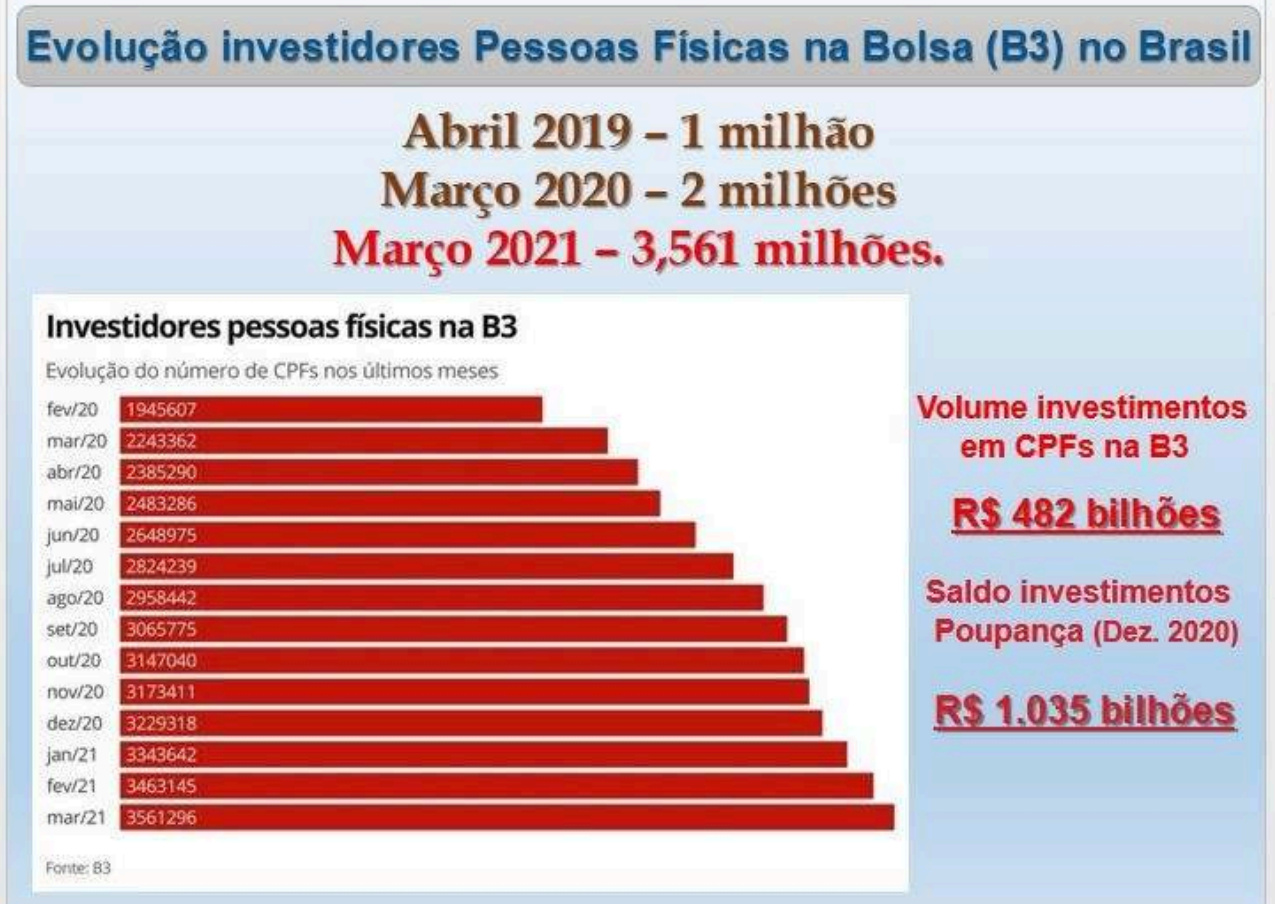

34. É esse movimento que tem levado a Anbima a se vangloriar do mercado de capitais brasileiro, dizendo que esta evolução se deve ao fato dele ser autorregulamentado. Assim, seu CEO disse em 2018: "a autorregulação da Anbima, é um dos principais motivos para a atração de investimentos nos fundos financeiros no Brasil. Se trata de um modelo privado criado pelo próprio mercado de forma voluntária e independente".

35. O superintendente geral da Anbima também afirmou na ocasião que o Mercado de Capitais tem como projeto a substituição do BNDES e do Estado pelo mercado. "O pleito e objetivo é que a atuação do BNDES seja apenas complementar e principalmente nas fases iniciais (maior risco). A ideia é a expansão do crédito privado e de mercado de longo prazo em substituição ao Estado". Superintendente geral da Anbima citou ainda que: "em 2018, o $\mathrm{n}^{\mathrm{o}}$ de ofertas de debêntures do mercado de capitais foi no valor de $\mathrm{R} \$$ 200 bilhões, enquanto o BNDES teria liberado apenas R\$ 60 bilhões".

37 36. Em síntese, o projeto em curso do mercado de capitais é:

a. Substituir BNDES.

b. Dirigir políticas econômicas no lugar do Estado;

c. Mercado de Capitais papel central e Centro Dinâmico da Economia brasileira.

d. Lógica acionária já é responsável por novas formas de governança empresarial.

37. Diante dessa realidade factual se torna necessário reconhecer que existe uma realidade distinta do que existia há duas décadas atrás. A lógica do neoliberalismo avançou bastante no país. Como diz os franceses Dardot \& Laval [14], o mercado avançou no esforço de substituir em parte o Estado, no controle das políticas e também no financiamento e na formulação das políticas em diferentes setores. E, desta forma também foi aumentando o controle e a manipulação sobre a política e as relações de poder. 

entre o capital nacional e os fluxos globais que envolvem, companhias de seguro, auditoria, grandes escritórios de advocacia, bolsa de valores, mercado de capitais (títulos, derivativos, debêntures, letras, etc.), fundos financeiros privados e soberanos, fundos de pensão, bancos centrais, bancos tradicionais, meios de pagamento (Shadow banking), etc. que juntos compõem o Circuito financeiro global. [2] [15]

Figura 5 - Esquema gráfico do circuito financeiro global

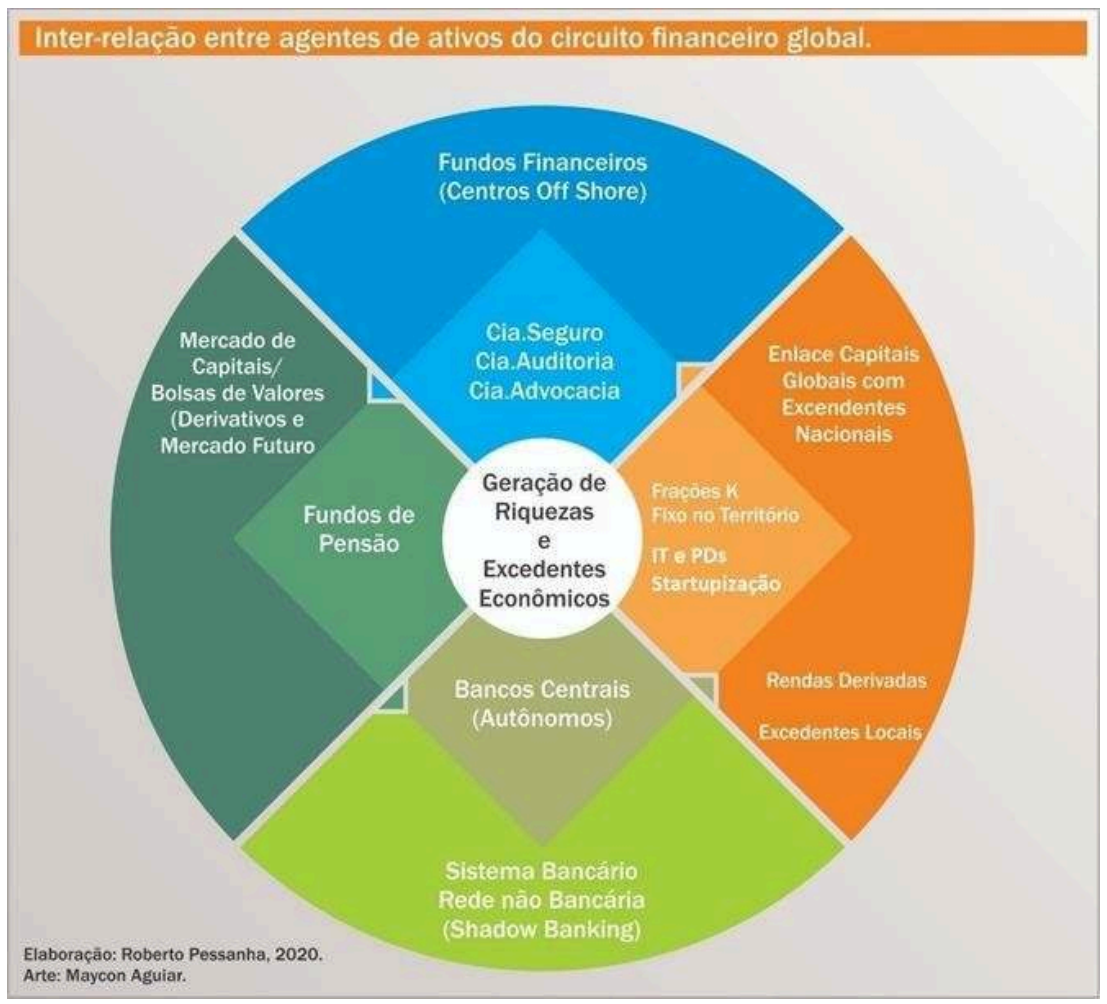

42. Os fluxos de capitais que se movimentam entre a base da pirâmide do circuito do valor e o andar de cima, alimentando com excedentes econômicos, os donos dos dinheiros que já controlam os ativos de forma transfronteiriça e com enlaces entre 
capitais nacionais e globais. Nesse processo se assiste, à desverticalização e desmonte de setores (petróleo) estatizados, que adiante são re-verticalizados pelas grandes corporações globais, hoje controladas pelos grandes fundos (BlackRock, JP Morgan, ...), forme mostrado na figura 6. (PESSANHA, 2019, p. 184) [2]

Figura 6: Movimento de desverticalização e re-verticalização do capital entre o nacional e o global.

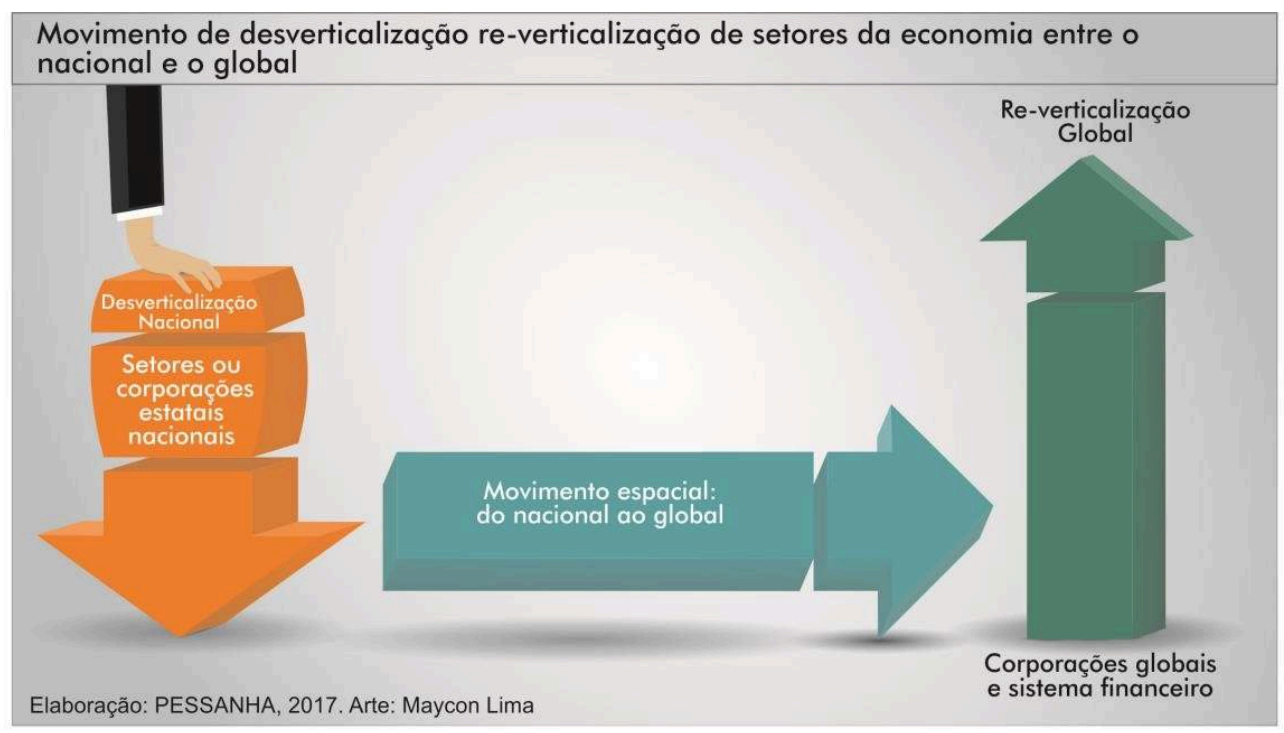
anseios da maioria do povo brasileiro. As propostas de ação exigem um debate amplo que reúna diferentes visões e experiências, busque interpretações mais próximas possíveis da realidade e um conjunto de medidas alternativas necessárias para a retomada do protagonismo do Estado e de um projeto inclusivo de desenvolvimento territorial com redução das desigualdades. 


\section{BIBLIOGRAFIA}

ARRIGHI, G. A ilusão do desenvolvimento. Petrópolis, Editora Vozes, 1997.

PESSANHA, R. M. A 'indústria' dos fundos financeiros: potência, estratégias e mobilidade no capitalismo contemporâneo. Rio de Janeiro: Consequência, 2019.

MARX, Karl. O capital. Boitempo: São Paulo, 2014.

Matéria de O Globo em 7 de maio de 2021, p. 23. Abílio Diniz lança gestora com investimento mínimo de R $\$ 1$ mil. Família e sócios fazem aporte de $\mathrm{R} \$ 1,75$ bi em fundo multimercado da empresa. Disponível em: https://blogs.oglobo.globo.com/capital/post/abilio-diniz-quer-cuidardo-seu-dinheiro- e-lanca-gestora-com-investimento-minimo-de-r-1-mil.html

Artigo do autor em 8 de maio de 2021 no portal 247. "Family Office" dos Diniz é um bom "case" da estratégia de financeirização de fração da nossa burguesia. Disponível em: https:// www.brasil247.com/blog/family-office-dos-diniz-e-um-bom-case-da-estrategia-definanceirizacao-de-fracao-da-nossa-burguesia

Sobre as mudanças na forma de intermediação financeira, uso aqui interpretações entrelaçadas com as investigações do professor-pesquisador Daniel Sanfelici, Departamento de Geografia da UFF, em sua apresentação no "Workshop Espaço e Poder: Infraestrutura, Financeirização e Território” no IPPUR-UFRJ, no dia 25 jun. 2019. Daniel Sanfelici pesquisa a Economia Política da Financeirização: aspectos teóricos e instrumentos financeiros vinculados ao setor imobiliário. Link de sua apresentação no IPPUR-UFRJ: https://www.youtube.com/watch? $\mathrm{v}=\mathrm{mmrxPSM} 8 \_\mathrm{x} 4 \& \mathrm{t}=793 \mathrm{~s}$

MAZZUCATO, M. O Estado empreendedor - desmascarando o mito do setor público vs. o setor privado. Recife: Portfólio-Penguin, 2014.

Matérias sobre venda de subsidiárias da Petrobras (gasodutos, refinarias, etc.) para fundos financeiros.

Sobre desmonte da Petrobras para entrega das subsidiárias a fundos de investimentos estrangeiros: Reportagem do site G1 em 13 out. 2017. Lava Jato levou empresas a vender mais de R\$ 100 bilhões em ativos desde 2015. Disponível em: https:/g1.globo.com/economia/negocios/ noticia/lava-jato-levou-empresas-a- vender-mais-de-r-100-bilhoes-em-ativos-desde-2015.ghtml Sobre venda da malha de gasodutos da Petrobras:

Matéria da Folha de São Paulo em 23 set. 2016. PAMPLONA, Nicola. Petrobras aprova venda de gasodutos à Brookfield por R\$ 5,2 bilhões. Disponível em: https://www1.folha.uol.com.br/ mercado/2016/09/1816100-brookfield-paga-us-52-bilhoes-para-ter-90-de- gasoduto-dapetrobras.shtml

Sobre a venda de refinarias da Petrobras a fundos estrangeiros:

Matéria do Estadão em 24 de março de 2021. Petrobrás fecha venda de refinaria na Bahia para fundo árabe por US\$1,65 bi. Venda para o fundo Mubadala foi a primeira, de um total de oito refinarias que entraram na lista de privatização da estatal; para conselheiros, no entanto, valor ficou abaixo do preço de mercado. Disponível em: https://economia.estadao.com.br/noticias/ geral,petrobras-fecha-venda-de-refinaria-na-bahia- para-fundo-arabe-por-us-1-65- bi, 70003659459\#: :text=RIO\%20\%2D\%200\%20conselho\%20de\%20administra\%C3\%A7\%C3\%A3o,como\%20gas olina\%20e\%20\%C3\%B3leo\%20diesel. 
Fundos financeiros passam a controlar médias empresas e negócios de menor porte transformada em ativos.Caso da rede Hortifuti vendida a um fundo de investimentos suíço Partners Group: Postagem no blog Roberto Moraes em 6 de novembro de 2018. Fundos financeiros agora também nos hortifrutis: seu avanço e mobilidade estão moldando o capitalismo contemporâneo e o modus de vida das pessoas. Disponível em: http://www.robertomoraes.com.br/2018/11/fundosfinanceiros-agora-tambem- nos.html

Matéria de O Globo, coluna Capital, em 14 de maio de 2021. Na fila para estrear na B3, Hortifruti inaugura loja conceito no Rio, após reforma e R\$ 6 milhões. Disponível em: https:// blogs.oglobo.globo.com/capital/post/na-fila-para-estrear-na-b3-hortifruti-inaugura-lojaconceito-no- rio-apos-reforma-de-r-6-milhoes.html

Caso de Fundos imobiliários (FII) ampliando rendimentos como proprietários de concessão de cemitérios durante a pandemia da Covid:

Matéria do Valor em 25 de maio de 2021. Retorno de fundo imobiliário do ramo funerário se destaca. O fundo CARE11, da gestora Zion Invest, é considerado pioneiro no Brasil. Disponível em: https://valor.globo.com/financas/noticia/2021/05/25/retorno-de-fundo-imobiliario-do-ramofunerario-se- destaca.ghtml?fbclid=IwAR1EAwxrgq73pB7Tww8qhYSJ29RQTnr7L9ze220ke2HSU0Z98KugDuF2lc

Caso da privatização e leilão de concessão da Cedae.

Artigo do autor no Portal $247 \mathrm{em} 30$ de abril de 2021. Fundos financeiros deitam na farra da entrega fatiada da Cedae. Disponível em: https://www.brasil247.com/blog/fundos-financeirosdeitam-na-farra-da-entrega- fatiada-da-cedae

Artigo no Portal Outras Palavras em 1 de junho de 2021. O mercado das águas e o suspeito leilão da Cedae. Maior empresa pública do RJ, que abastece 17 milhões, foi entregue a fundos internacionais aos quais só importa lucrar. Pesquisadores apontam indícios de fraude, acordo prévio entre grupos que participaram do leilão e enormes prejuízos sociais. Disponível em: https://outraspalavras.net/crise-brasileira/o-mercado-das-aguas-e-o- suspeito-leilao-da-cedae/

Anbima. Associação Brasileira das Entidades dos Mercados Financeiro e de Capitais. A Anbima se coloca com a principal instituição que representa o mercado de capitais no país. Além da Anbima, minha pesquisa sobre os fundos financeiros levantou a existência de mais de duas dezenas de associações, fóruns e agências que organizam e articulam os interesses desta fração do capital.

Matéria do Valor em 7 de janeiro de 2021. Fundos imobiliários podem passar de 2 milhões de investidores. Outra boa notícia é a possibilidade de recuperação de preços no médio prazo das cotas de fundos especializados em áreas mais atingidas pela pandemia, como shoppings e lajes corporativas. Disponível em:https://valorinveste.globo.com/produtos/fundos-imobiliarios/ noticia/2021/01/07/fundo-imobiliario-pode-passar-de-2-milhoes-de-investidores.ghtml

Matéria do Portal G1 em 6 de abril de 2021. Bolsa brasileira atinge marca de 3,5 milhões de investidores pessoas físicas. Nos 3 primeiros meses do ano, número de novos ingressantes chega a 331,9 mil. Pessoa física já tem R \$ 482bilhões em ações na B3. Disponível em: https:// g1.globo.com/economia/noticia/2021/04/06/bolsa-brasileira-atinge-marca-de-35-milhoes- deinvestidores-pessoas-fisicas.ghtml

DARDOT, P.; LAVAL, C. A nova razão do mundo - Ensaio sobre a sociedade neoliberal. São Paulo: BoiTempo, 2017.

MÉNDEZ, R. La Telaraña Financiera: una geografia de la financiarización y su crisis. Santiago: RiL editores, 2018. 
PS.: Sugiro, ainda, pelo menos três outros importantes autores, para uma melhor compreensão das transformações mais recentes do capitalismo e da hegemonia financeira na contemporaneidade. Abaixo eles estão listados pela data de publicação:

CHESNAIS, F. O capital portador de juros: acumulação, internacionalização, efeitos econômicos e políticos. In: CHESNAIS, F. (org.). A finança mundializada: raízes sociais e políticas, configuração, consequências. São Paulo: Boitempo, 2005, p. 35-67.

HARVEY, D. A loucura da razão econômica. São Paulo: BoiTempo, 2018.

DOWBOR, Ladislaw. O capitalismo se desloca: novas arquiteturas sociais. Edições Sesc São Paulo: São Paulo, 2020.

\section{RESUMOS}

Não é razoável pensar a retomada de um projeto nacional-desenvolvimentista que promova redução das desigualdades e integração regional, sem que se leve em conta que hoje temos um Brasil bem distinto de duas décadas atrás. Como em outras partes do mundo, as finanças alcançaram a condição de centro dinâmico da economia promovendo enorme extração de valor da economia real. Tudo está se transformando em ativos em meio a colossais inovações financeiras que usando os fundos e as plataformas digitais realizam enorme captura de excedentes num "capitalismo de gestão de ativos". Dominação tecnológica que amplia a hegemonia financeira. 0 mercado de capitais passou a dirigir políticas setoriais no lugar do Estado, numa lógica ainda mais radical de extração de valor do trabalho na economia brasileira. Em breve diagnóstico, este texto propõe um debate mais amplo sobre como confrontar essa realidade em curso num processo que não é natural e sim opção neoliberal e excludente. Na essência é necessário retomar o protagonismo do Estado, a soberania da Nação e nossa capacidade de intervenção em políticas econômicas-setoriais-regionais-territoriais e sociais. Só a política pode ou não realizar essa tarefa.

Dans tout le monde, les finances ont atteint la condition de centre dynamique de l'économie en promouvant énorme extraction de valeur de l'économie réelle. Fonds, plateformes numériques et innovations financières capturent les surplus en déssinant un "capitalisme de gestion d'actifs ". Une fois que l'État a été remplacé par le marché de capitaux en ce qui concerne aux politiques sectorielles, le résultat est l'aggravation de l'extraction de surplus dans l'économie brésilienne. En s'opposant à cette situation d'exclusion néolibérale, il faut reprendre le protagonisme de l'État, la souverainété de la nation et la capacité d'intervention autour des politiques sectorielles. Cette tâche ne peut pas être réalisée qu'à travers de la politique.

No es razonable pensar en la retomada de un proyecto de desarrollismo nacional que promueva la reducción de las desigualdades y la integración regional, sin tener en cuenta que hoy tenemos un Brasil muy diferente al de hace dos décadas. Como en otras partes del mundo, las finanzas han alcanzado el estatus de centro dinámico de la economía, promoviendo una enorme extracción de valor de la economía real. Todo se está convirtiendo en activos en medio de colosales innovaciones financieras que el uso de fondos y plataformas digitales logran una enorme captura de excedentes en el "capitalismo de gestión de activos". Dominación tecnológica que expande la hegemonía financiera. El mercado de capitales pasó a dirigir políticas sectoriales en lugar del Estado, en una lógica aún más radical de extraer valor del trabajo en la economía brasileña. En diagnóstico reducido, este texto propone un debate más amplio sobre cómo afrontar esta realidad en un proceso que no es natural, sino una opción neoliberal y excluyente. En esencia, es necesario retomar el protagonismo del Estado, la soberanía de la Nación y nuestra capacidad de 
intervenir en las políticas económicas-sectoriales-regionales-territoriales y sociales. Solo la política puede o no puede realizar esta tarea.

It is not reasonable to think about the resumption of a national developmental project that promotes reduction of inequalities and regional integration, without taking into account that today we have a very different Brazil from two decades ago. As in other parts of the world, finance has reached the status of dynamic center of the economy by promoting enormous value extraction from the real economy. Everything is turning into assets amid colossal financial innovations that using digital funds and platforms perform huge surplus capture in "asset management capitalism". Technological domination that expands financial hegemony. The capital market began to direct sectoral policies in place of the State, in an even more radical logic of extracting value from labor in the Brazilian economy. Soon, this text proposes a broader debate on how to confront this ongoing reality in a process that is not natural but a neoliberal and exclusionary option. In essence it is necessary to resume the role of the State, the sovereignty of the nation and our capacity to intervene in economic-sectoral-regional-territorial and social policies. Only the policy can or cannot accomplish this task.

\section{ÍNDICE}

Palavras-chave: financeirização, capitalismo financeiro, plataformas digitais, gestão de ativos, território.

Keywords: financialization, financial capitalism, digital platforms, asset management, territory

Mots-clés: financiarisation, capitalisme financier, plateformes numériques, gestion d'actifs, territoire.

Palabras claves: financiarización, capitalismo financiero, plataformas digitales, gestión de activos, territorio

\section{AUTOR}

\section{ROBERTO MORAES PESSANHA}

Professor Titular, Instituto Federal Fluminense. Email: robertomoraespessanha@gmail.com 